\title{
Topic issue: men's health in 2019
}

\author{
Dean Elterman ${ }^{1,2,3,4}$
}

Published online: 10 May 2019

(c) Springer-Verlag GmbH Germany, part of Springer Nature 2019

\section{Dean Elterman}

In Urology, we often fail to appreciate the greater picture of what men's health means. We focus expertly on diseases of the prostate and male genitourinary system, and increasingly their relationship to other organ systems, i.e., cardiovascular [1-3]. We now realize how metabolism and heart-health impact men's urinary and sexual function, and many urologists are screening for these non-urologic diseases [4-8]. This is great news as perhaps a decade or so ago, I would not have been able to write this statement [9, 10]. Let us take a moment though to take a step back and look at men's health from a more global perspective. The WHO still reports lower life expectancy for men in every nation of the world with healthy life expectancy (HALE), defined as average number of years that a person can expect to live in "full health" by taking into account years lived in less than full health due to disease and/or injury, remains significantly truncated for men [11]. Men's health is not in competition against women's health. On the contrary, they are different sides of the same coin. To have safe and prosperous societies, its citizens must remain healthy and productive. Premature male morbidity and mortality impacts most greatly those who are left behind, namely women, children, communities, and economies. Much of the developing world still relies heavily upon a male workforce to support their families. If preventable illness, workplace accidents, suicide and mental illness were more fulsomely addressed, we would see a precipitous drop in the top causes on young men's disability and premature death [12].

\footnotetext{
Dean Elterman

dean.elterman@uhn.ca

1 Division of Urology, University of Toronto, Toronto, Canada

2 Urologic Surgeon, University Health Network, Toronto, Canada

3 Krembil Research Institute, Toronto, Canada

4 Innovators and Technology, Societe Internationale D’Urologie, Montreal, Canada
}

The Societe Internationale D'Urologie (SIU) is representative truly of global urology, with active members from every continent and every sub-discipline within urology. Care for men around the world, of all socioeconomic backgrounds is one of the fundamental missions of the SIU. This special issue has arisen from the SIU Innovators committee, which provides a forum for early career urologists to engage in the SIU, international collaboration, and friendship. The contributors to this edition are all extraordinary early-career academic urologists committed to engaging and furthering the mission of the SIU and their local communities. Men's health takes many forms when it comes to research within urology. In this issue, we will explore men's sexual health, looking at The Effect of Diet on LUTS, BPH and ED by Chughtai et al. in New York [13] and a Global Review of Injectables for ED by Lawrentschuk et al. in Melbourne [14]. Prostate health remains a key focus for the urologic community and as such, we will take a look at Smarter Screening For Prostate Cancer by Perlis et al. in Toronto [15], examine the innovative ways we can now treat BPH in Beyond Meds: Office-Based Procedures for Benign Prostatic Enlargement by Chung in Sydney [16] as well as gain insight into the often difficult to manage male patient with Chronic Pelvic Pain/Chronic Prostatitis-Where Do We Stand by Doiron and Nickel in Kingston [17]. Managing the hormonal and fertility concerns of men will often fall upon the urologist, thus herein we will discuss The State of the Art in Testosterone Therapy by Krakowsky in Toronto [18] and Optimizing Male Fertility by Cardoso in Sao Paulo [19]. Finally, in an ever more connected world through the Internet, men are seeking health advise online. The quality of the resources available is variable and knowing where to direct patients is now an important part of our counselling, studied here in Men's Health on the Web: An Analysis of Current Resources by Lawrentschuk et al. in Melbourne [9].

Finally, on behalf of the SIU Innovators committee, I would like to dedicate this issue to one of our members, Dr. Daniel Christidis, who we lost tragically this year. Dan was a much admired and beloved friend to many around the world. He was already regarded as a future leader in academic 
urology and a significant contributor to the SIU and the Australian urologic community. Dan was everything we aspire to be-warm and engaging with his friends and family, kind and caring with his patients, thoughtful and respected amongst his peers. When reflecting upon what men's health means to me, the loss of Dan has personally shown me the profound and far-reaching impact of losing just one man too early in life has on those who are left behind.

\section{References}

1. Yee CH, Yip JSY, Cheng NMY, Kwan CH, Li KM, Teoh JYC, Chiu PKF, Wong JH, Chan ESY, Chan CK, Hou SSM, Ng CF (2019) The cardiovascular risk factors in men with lower urinary tract symptoms. World J Urol 37(4):727-733

2. Fan Y, Hu B, Man C, Cui F (2018) Erectile dysfunction and risk of cardiovascular and all-cause mortality in the general population: a meta-analysis of cohort studies. World J Urol 36(10):1681-1689

3. Bouwman II, Voskamp MJ, Kollen BJ, Nijman RJ, van der Heide WK, Blanker MH (2015) Do lower urinary tract symptoms predict cardiovascular diseases in older men? A systematic review and meta-analysis. World J Urol 33(12):1911-1920

4. Zou C, Gong D, Fang N, Fan Y (2016) Meta-analysis of metabolic syndrome and benign prostatic hyperplasia in Chinese patients. World J Urol 34(2):281-289

5. Zhang X, Zeng X, Dong L, Zhao X, Qu X (2015) The effects of statins on benign prostatic hyperplasia in elderly patients with metabolic syndrome. World J Urol 33(12):2071-2077

6. Cantiello F, Cicione A, Autorino R, Salonia A, Briganti A, Ferro M, De Domenico R, Perdonà S, Damiano R (2014) Visceral obesity predicts adverse pathological features in urothelial bladder cancer patients undergoing radical cystectomy: a retrospective cohort study. World J Urol 32(2):559-564

7. Chang ST, Chu CM, Hsu JT, Chung CM, Pan KL, Hsiao JF, Lin YS (2010) Scrutiny of cardiovascular risk factors by assessing arterial stiffness in erectile dysfunction patients. World J Urol 28(5):625-630

8. Russo GI, Cimino S, Fragalà E, Privitera S, La Vignera S, Condorelli R, Calogero AE, Chisari M, Castelli T, Favilla V, Morgia G (2015) Relationship between non-alcoholic fatty liver disease and benign prostatic hyperplasia/lower urinary tract symptoms: new insights from an Italian cross-sectional study. World J Urol 33(5):743-751

9. Teh J, Wei J, Chiang G, Nzenza TC, Bolton D, Lawrentschuk N (2019) Men's health on the web: an analysis of current resources. World J Urol. https://doi.org/10.1007/s00345-019-02670-5

10. Martin SA, Haren MT, Marshall VR, Lange K, Wittert GA, Members of the Florey Adelaide Male Ageing Study (2011) Prevalence and factors associated with uncomplicated storage and voiding lower urinary tract symptoms in community-dwelling Australian men. World J Urol 29(2):179-184

11. Life expectancy and Healthy life expectancy, Data by WHO region. http://apps.who.int/gho/data/view.main.SDG2016LEX REGv?lang=en. Accessed 06 Apr 2018

12. Leading Causes of Death (LCOD) by Age Group, All MalesUnited States, 2015. https://www.cdc.gov/healthequity/lcod/ men/2015/all-males/index.htm. Accessed 29 April 2019

13. ElJalby M, Thomas D, Elterman D, Chughtai B (2018) The effect of diet on BPH, LUTS and ED. World J Urol. https://doi. org/10.1007/s00345-018-2568-0

14. Duncan C, Omran GJ, Teh J, Davis NF, Bolton DM, Lawrentschuk N (2019) Erectile dysfunction: a global review of intracavernosal injectables. World J Urol. https://doi.org/10.1007/s00345-01902727-5

15. Tan GH, Nason G, Ajib K, Woon DTS, Herrera-Caceres J, Alhunaidi O, Perlis N (2019) Smarter screening for prostate cancer. World J Urol. https://doi.org/10.1007/s00345-019-02719-5

16. Tran PU, Chung ASJ (2019) Beyond medications: office-based procedures for benign prostatic obstruction. World J Urol. https ://doi.org/10.1007/s00345-019-02720-y

17. Doiron RC, Shoskes DA, Nickel JC (2019) Male CP/CPPS: where do we stand? World J Urol. https://doi.org/10.1007/s00345-01902718-6

18. Aditya I, Grober ED, Krakowsky Y (2019) Peyronie's disease and testosterone deficiency: is there a link? World J Urol. https://doi. org/10.1007/s00345-019-02723-9

19. Cardoso JP, Cocuzza M, Elterman D (2019) Optimizing male fertility: oxidative stress and the use of antioxidants. World J Urol. https://doi.org/10.1007/s00345-019-02656-3

Publisher's Note Springer Nature remains neutral with regard to jurisdictional claims in published maps and institutional affiliations. 